\title{
Representación audiovisual de personajes de ficción en el carnaval de Cádiz. Hipercultura popular
}

\section{Audiovisual representation of fictional characters at the Cádiz carnival. Popular hyperculture}

\author{
Estrella Fernández Jiménez \\ Universidad de Sevilla \\ https://orcid.org/oooo-0001-9589-5190 \\ estrellaffjj@us.es
}

Resumen: La manera de comunicar que tiene el carnaval de Cádiz lo hace una manifestación cultural versátil. Mediante la trascripción y visionado de coplas extraemos cómo los autores interpretan fenómenos de la cultura popular como son los súper héroes, personajes de cine o de la literatura romántica y los convierten en agrupaciones carnavalescas aunando fenómenos de distinto origen. Esto da lugar a otro producto cultural mediante el palimpsesto (Genette) y la apropiación de signos y símbolos. Mostramos cómo a través de la representación y escritura de coplas se produce una hipercultura popular.

Palabras clave: comunicación, carnaval, Cádiz, cultura popular, palimpesto.

\begin{abstract}
The way of communicating that the Cádiz carnival has makes it a versatile cultural manifestation. Throght the transcription and viewing of coplas we extract how the authors interpret phenomena of popular culture such as superheroes, characters from movies or romantic literature and turn them into carnival groups combining phenomena of different origin. This gives rise to another cultural product through the palimpsest (Genette) and the appropriation of signs and symbols. We show how a popular hypercultura is produced through the representation and writing of coplas.
\end{abstract}

Keywords: communication, carnival, Cádiz, popular culture, palimpsest.

Recibido: 7 de octubre de 2020

Aceptado con modificaciones: 11 de diciembre de 2020

Aceptado: 17 de diciembre de 2020 


\section{Introducción}

El carnaval de Cádiz es una de las fiestas españolas y universales más versátiles, ya que puede ser estudiada desde diversas perspectivas. Este trabajo lo hará desde su perspectiva comunicacional, así como desde algunos aspectos de la semiótica ya que se ponen en juego elementos simbólicos, visuales y acústicos. Clave en este estudio serán las teorías literarias de Genette.

Este carnaval, duramente reprimido e incluso prohibido en la época de la dictadura franquista en España, pudo sobrevivir y ha llegado a ser hoy uno de los emblemas distintivos de su ciudad, Cádiz, y cada vez más a nivel regional ${ }^{1}$. Otro aspecto importante que le sucede a esta manifestación cultural es la necesidad de mantener el equilibrio entre innovación y tradición (Fernández, 2018). Actualmente, no se circunscribe solo en el periodo carnavalesco si no que cobra relevancia en Cádiz durante todo el año.

Bajtin (1990) sostiene que las características del carnaval en la época del Renacimiento son: Inversión, Poder, libertades y libertinaje; Fiesta y Cultura Popular; Teatralidad; Vocabulario; Disfraz y Máscara; Risa; Gastronomía y Banquete; y Música. Como vemos, la cultura aparece entre estas características. Y el Carnaval de Cádiz es contenedor de todas estas particularidades además de sobresalir en ser portavoz de la definición sobre cultura popular que nos muestra el Diccionario de la Real Academia Española "Conjunto de las manifestaciones en que se expresa la vida tradicional de un pueblo" y "Si hay algo en el universo de lo humano que no sea totalmente dado, sino construido, eso es la cultura" (Vázquez, 1994: 18). No solo eso, como vamos a exponer seguidamente, el carnaval de Cádiz muestra manifestaciones tradicionales de Andalucía y Cádiz mediante los estereotipos sociales -de ahí la palabra "tipo" para describir sus disfraces y atuendos. Cuando hablamos de "tipo" en el carnaval de Cádiz no solo hacemos referencia al disfraz. Son las características del personaje que ese año encarnará una agrupación determinada. Atiende más a la personalidad e idiosincrasia del personaje a representar ${ }^{2}-$, y además se nutre de la cultura popular de otros lugares. También se ajusta dentro de la definición extendida que dice que la cultura popular es aquella que no se aprende en las escuelas 3 . Y como sostiene Bajtin (1990) forma parte de la cultura cómica popular. Al igual que ocurriera con el Jazz o los cómics que ya están implantados en diferentes tipos de enseñanzas, el carnaval de Cádiz desde hace pocos años se comienza a tratar desde diferentes ópticas académicas. En los últimos cinco años se han defendido cinco tesis doctorales sobre el carnaval de Cádiz: El carnaval de Cádiz como generador de información, opinión y contrapoder: análisis crítico de su impacto en línea y fuera de línea (Sacaluga Rodríguez, 2014), El tipo en el carnaval de Cádiz. Propuesta para una catalogación (Barceló Calatayud, 2014), El carnaval silenciado. Golpe de estado, guerra, dictadura y represión en el febrero gaditano (1936-1945) (Moreno Tello,

\footnotetext{
${ }^{1}$ Ya se hacen tertulias fuera de la capital gaditana como puede ser en Sevilla. Jornada de Carnaval Week "La chirigota según Sevilla" 5 de marzo de 2020. Recuperado de:

https://www.youtube.com/watch?v=dpWPVvaJzKo

${ }^{2}$ Sobre este tema puede profundizarse en la obra El tipo en el carnaval de Cádiz. Propuesta para una catalogación (Barceló, 2015).

3 Aunque hemos de señalar que en 2018 se creó en la Universidad de Cádiz la Cátedra de Carnaval que promueve y fomenta de manera académica el conocimiento y difusión de este fenómeno que aquí tratamos.
} 
2015), El Carnaval de Cádiz como factoría de literatura popular. Un acercamiento al proceso de creación y transmisión de sus coplas (Páramo Fernández-Llamazares, 2016), El potencial comunicativo de las chirigotas gaditanas y su realización televisiva (Fernández Jiménez, 2016). Y en 2002, Música y agrupaciones de carnaval: Huelva y Cádiz (García Gallardo, 2002), (dos en Cádiz, dos en Madrid, una en Sevilla y una en Huelva). En todas ellas se subraya el peso que la cultura popular tiene en este fenómeno social. En cuatro de ellas, Barceló, Sacaluga, Páramo y Fernández se muestran peculiaridades comunicativas de este carnaval que nunca antes habían sido resaltadas: El cuidado en la elaboración de los tipos/disfraces y lo que significan para la fiesta, la cantidad de información que generan en la web, que puede considerársele un género literario (de ahí que podamos aplicar la teoría mostrada en Palimpsesto), y el potencial que tiene como producto televisado, creando así su extensión a nivel regional y nacional. Esto denota el interés que suscita a nivel académico sin contar las numerosas actuaciones que algunas agrupaciones tienen por toda la geografía española en cualquier época del año una vez terminado el carnaval. Algunas agrupaciones han sido contratadas en países de Latinoamérica.

Como cualquier otra creación artística, cada autor tiene su manera de escribir. Hay autores que como en carnaval se suele decir "se meten más en el tipo" que otros. Hacen las funciones de actor de teatro, que, por un periodo de tiempo establecido, lo que dure la representación, no es él o ellos, sino su personaje. Esta empatía aparece desde el momento de composición de letra (y música). Un autor de carnaval, cuando escribe el repertorio de una agrupación debe transformar su manera de escribir a cómo lo haría o qué diría el personaje al que va representando: un niño, un indio, una momia, un perro, un borracho, un árbitro, un bebé, una vidente, un fraile, un cocinero, un mosquito, un arlequín, un policía, un caníbal, un reguetonero, un bombero, un pez, un gondolero, un budista, etc. Y tendrá que adaptar su escritura a lo que diría el personaje representado (Fernández, 2020). Otro aspecto a destacar es que los autores, letristas y músicos del carnaval de Cádiz no son profesionales con referencia a la definición de que su sustento principal de vida sea esta creación artística. Lo hacen a modo de hobby, pese a que para algunos intérpretes y/o autores, ya comienza a ser su principal fuente de ingresos. Cada año los autores se reinventan. Puede ocurrir que varias agrupaciones se inspiren en el mismo personaje de ficción, pero estas nunca van a ser iguales. Aprovechamos para advertir a los no instruidos en la fiesta gaditana que cada autor prepara cada año un repertorio nuevo, es decir, unos cuarenta y cinco minutos aproximadamente de músicas y letras nuevas cada año4 (sumando presentación/parodia, pasodobles/tangos, cuplés, popurrí/tema libre).

La temática general de las agrupaciones sigue surgiendo de los ítems que ya numeró Ramón Solís en 1966, como pueden ser: raigambre popular; novedades tecnológicas; política; temas sociales; fútbol; etc. Con nuestra observación de este fenómeno cultural hemos percibido un subgénero de temática interpretativa de las agrupaciones que la que aquí tratamos: los personajes de ficción.

4 Cálculo aproximado según las agrupaciones oficiales. En las agrupaciones callejeras/ilegales el tiempo no está estipulado, ni tampoco la cantidad de repertorio, pero entre interpretar las coplas, más ciertas paradas o interrupciones características de la calle, una actuación de una agrupación callejera puede prolongarse hasta una hora o más. No puede hablarse con exactitud en este aspecto. 
Una de las dificultades que encontramos al estudiar el carnaval de Cádiz es que siempre, como vamos a mostrar, está en continuo cambio, con lo cual las investigaciones quedan fácilmente obsoletas.

En esta investigación mostramos cómo algo que académicamente ha estado denostado puede ser analizado desde múltiples perspectivas tan ricas como las teorías literarias de Genette.

\section{Objetivos}

Con este trabajo queremos alcanzar los siguientes objetivos:

Mostrar otra vertiente de estudio que el carnaval de Cádiz tiene como fenómeno cultural, ya que es cultura popular y a su vez se nutre de otras culturas5.

Aumentar la producción científica de este objeto de estudio para presentes y futuros investigadores, así como a los cada vez más numerosos alumnos de trabajo fin de grado y trabajo fin de máster que deciden investigar sobre el tema.

Exponer por primera vez cómo personajes de la cultura popular (fílmicos y de cómics) son transformados por el carnaval de Cádiz dando un producto nuevo. Demostramos así que, esta fiesta, no solo se trata solo de cultura, sino que al mismo tiempo se dan casos de hipercultura popular, esto es, cultura que hace referencia a cultura popular.

\section{Metodología}

En este artículo nos valemos de la metodología cualitativa ya que es la más adecuada para acercarnos al fenómeno estudiado. Mediante la observación, extraemos cualidades y características pertinentes al estudio. Hemos procedido a buscar en agrupaciones del Concurso Oficial de Agrupaciones Carnavalescas de Cádiz (COAC) aquellas que en su nombre o tipo hicieran alusión a creaciones o personajes de la cultura popular mundial. Una vez recabada esta información, tomamos como parte de análisis del repertorio la presentación de dos de ellas. Las partes del repertorio de una agrupación de carnaval son las siguientes:

- Chirigotas y comparsas: presentación, pasodobles, cuplés y popurrí.

- Coros: presentación, tangos, cuplés y popurrí.

- Cuartetos: parodia, cuplés, tema libre/popurrí. ${ }^{6}$

Tomamos la presentación y no otra parte del repertorio ya que dan las claves generales con las que desarrolla el personaje interpretado. Para la elaboración de este trabajo se seleccionaron dos en las que los rasgos eran evidentes y así poder usarlas de modelos y de las cuales hubiera material audiovisual. Debido a las extensiones del

5 Todavía hoy hay sectores de la sociedad que no incluyen al carnaval dentro de cultura. Controversia surgida por motivos políticos quizá, más que culturales e históricos como se observa en Bello (2019).

6 Para una pormenorizada explicación de estas partes del repertorio pueden consultarse los trabajos de Páramo (2017), Medina (2017), o Fernández (2016 y 2018). Se puede encontrar más información sobre la pre-producción, puesta en escena y evolución de coplas en Fernández (2020). 
presente trabajo, el número analizado es reducido, pero suficiente para transmitir la idea y objetivos de investigación.

Una vez seleccionadas las presentaciones, las transcribimos para mostrar de manera esclarecedora el contenido. Posteriormente, procedemos a comparar los rasgos fundamentales del hipotexto (creación matriz) con los elementos característicos transformados carnavalescamente que configuran el hipertexto (agrupación de carnaval).

Para resolver una de las dudas que esta investigación nos plantea, la cual es: en qué datos se basaron los autores para la creación de las composiciones, contactamos con los autores de las letras de carnaval vía telefónica ya que solo ellos podrían contestar esa pregunta. En el cuerpo de la investigación será indicada la respuesta.

\section{Marco teórico: carnaval de Cádiz y transdiscursividad}

\subsection{Cultura popular}

Como señalábamos con anterioridad, "Una definición operativa de cultura debe tener en cuenta lo siguiente: cultura es información no hereditaria que almacenan, transmiten y transforman los integrantes de una colectividad determinada" (Vázquez, 1994: 40). Nuestra colectividad determinada son las agrupaciones del carnaval de Cádiz y la información no hereditaria almacenada son las coplas. Como señala Roiz (1982: 113), en la fiesta popular no solo se rompen las normas en el trabajo, puesto que se puede dar el día libre, que sea fiesta local, sino también en la manera en que las personas se comunican, el grupo o la comunidad. También sucede que, durante carnaval, una persona que habitualmente es tímida o apocada no se comporta como tal.

Asegúrase que con la cara tapada se descubre más fácilmente el corazón y que a favor de la careta es lícito en estos días decir todo género de claridades. [...] Con qué gusto nos envolveríamos en un portier, nos pondríamos aunque solo fuese la mano por delante de los ojos y fingiendo la voz para que el señor Bugallal no nos conociese, le daríamos una broma a alguno de los hombres que ocupan el poder. [...] Pedro, trae un miriñaque, un miriñaque espantoso, una falda de seda y una capota. Vamos a vestirnos de mujer y al diablo las filosofías (Bécquer, 1862).

"Los movimientos de carnaval son medios naturales de expresión que se engarzan en muchos otros que resultan de la propia cultura popular" (López, 1998: 347). La forma en la que se comunica, se transmite, el carnaval de Cádiz o concretamente sus agrupaciones, es doble: local, puesto que en muchas ocasiones cantan a aspectos muy cercanos; y global ya que, desde hace tres décadas, gracias a los medios de comunicación las letras de las agrupaciones son escuchadas (y vistas) fuera de Cádiz (Osuna, 2009, y Fernández, 2018). Observamos cómo los tipos que las agrupaciones de carnaval muestran hibridación de culturas. Los grupos siembre han mostrado diferentes etnias, nacionalidades, etc., pero también han irrumpido e irrumpen con fuerza los tipos de referencias más audiovisuales, lo cual denota las constantes actualizaciones a las que se somete el carnaval de Cádiz para no resultar desfasado. Siempre en equilibrio entre innovación y tradición.

El tema de la máscara es más importante aun. Es el tema más complejo y lleno de sentido de la cultura popular. La máscara expresa la alegría de las sucesiones y 
reencarnaciones, la alegre relatividad y la negación de la identidad y del sentido único, la negación de la estúpida autoidentificación y conciencia consigo mismo; la máscara es una expresión de las transferencias, de las metamorfosis, de la violación de las fronteras naturales, de la ridiculización, de los sobrenombres; la máscara encarna el principio del juego de la vida, establece una relación entre la realidad y la imagen individual, elementos característicos de los ritos y espectáculos más antiguos. El complejo simbolismo de las máscaras es inagotable (Bajtin, 1990: 41 y 42).

Muchos superhéroes de la cultura popular llevan máscara, al igual que muchos carnavales, pero resulta que el carnaval de Cádiz, al ser un carnaval charlatán ${ }^{7}$, es decir, que la parte literaria y cantada (incluso hablada) es trascendental, el uso de máscaras en los intérpretes de las coplas se hace inviable.

\section{2. Palimpsestos}

Para explicar nuestro concepto de hipercultura popular nos basamos en la obra Palimpsesto de Genette (1989) que aunque hace referencia a la literatura, nosotros lo extrapolamos al carnaval de Cádiz que también consiste en literatura, como se expuso en el "Congreso Literatura y Humor"8, idea argumentada también por Páramo (2017). Aunque aparentemente el carnaval de Cádiz es un hecho solo performativo, es evidente que la carga literaria que posee (es un concurso y fiesta de coplas: letra y música) hace que se le puedan aplicar criterios literarios.

Una definición que nos ayuda a entender por qué traemos este concepto al presente estudio es la que nos ofrece el Diccionario de la Real Academia Española: Palimpsesto "Manuscrito antiguo que conserva huellas de una escritura anterior borrada artificialmente. Tablilla antigua en que se podía borrar lo escrito para volver a escribir"9. Es decir, es algo donde se observa que, deliberadamente, el producto resultante (en nuestro caso, la agrupación de carnaval) se basa o inspira en otra cosa conocida por un amplio sector del público al que va dirigido. "En el orden de las relaciones textuales, puede representarse mediante la vieja imagen del palimpsesto, en la que se ve, sobre el mismo pergamino, cómo un texto se superpone a otro al que no oculta del todo, sino que lo deja ver por transparencia” (Genette, 1989: 495).

Como vamos a mostrar, estas agrupaciones dejan ver esa transparencia ya sea en el contenido de las coplas, en el atuendo o en el nombre de la agrupación. Para entender mejor estos conceptos debemos detenernos en destacar las ideas fundamentales sobre la transtextualidad (relaciones entre textos) que sostiene Genette (1989).

Los conceptos presentados por Genette son: Intertextualidad, paratexto, metatextualidad, architextualidad, e hipertextualidad.

Intertextualidad es:

La presencia efectiva de un texto en otro. Su forma más explícita y literal es la práctica tradicional de la cita (con comillas, con o sin referencia precisa); en una forma menos explícita y menos canónica, el plagio [...] que es una copia no declarada pero literal; en

\footnotetext{
7 1. adj. Que habla mucho y sin sustancia. 2. adj. Hablador indiscreto. 3. adj. embaucador. 4. m. y f. Persona que se dedica a la venta ambulante y anuncia a voces su mercancía. $R A E$ 8 Celebrado en Jerez de la Frontera, Cádiz (España), (23, 24 y 25 de octubre de 2019).

9 La segunda acepción procede del Diccionario Nuevo Espasa Ilustrado (2002).
} 
forma todavía menos explícita y menos literal, la alusión, es decir, un enunciado cuya plena comprensión supone la percepción de su relación con otro enunciado al que remite necesariamente tal o cual de sus inflexiones, no perceptible de otro modo (Genette, 1989: 10).

Esto que acabamos de hacer es un intertexto, una cita literal.

El paratexto:

Título, subtítulo, intertítulos, prefacios, epílogos, advertencias, prólogos, etc.; notas al margen, a pie de página, finales; epígrafes; ilustraciones; fajas, sobrecubierta, y muchos otros tipos de señales accesorias, autógrafas o alógrafas, que procuran un entorno (variable) al texto y a veces un comentario oficial u oficioso del que el lector más purista y menos tendente a la erudición externa no puede siempre disponer tan fácilmente como desearía y lo pretende (Genette, 1989: 11 y 12).

Es decir, los paratextos enmarcan al texto.

La metatextualidad "es la relación -generalmente denominada 'comentario' - que une un texto a otro texto que habla de él sin citarlo (convocarlo), e incluso, en el límite, sin nombrarlo. [...] La metatextualidad es por excelencia la relación crítica” (Genette, 1989: 13). En el carnaval de Cádiz se denomina metacarnaval cuando las letras aluden al propio carnaval de Cádiz.

La architextualidad alude a su pertenencia taxonómica (Genette, 1989: 13), es decir, trataría sobre el género al que pertenece un texto (narrativa, poesía, etc.) que un lector le atribuye a un texto.

Y, por último, y base de este estudio, encontramos la hipertextualidad que es:

Toda relación que une un texto B (que llamaré hipertexto) a un texto anterior A (al que llamaré hipotexto) en el que se injerta de una manera que no es la del comentario. [...] Para decirlo de otro modo, tomemos una noción general de texto en segundo grado [...] o texto derivado de otro texto preexistente. Esta derivación puede ser del orden, descriptivo o intelectual, en el que un metatexto [...]"habla" de un texto [...] Puede ser de orden distinto, tal que B no hable en absoluto de A, pero que no podría existir sin A, del cual resulta al término de una operación que calificaré, también provisionalmente, como transformación, y al que, en consecuencia, evoca más o menos explícitamente, sin necesariamente hablar de él y citarlo (Genette, 1989: 14 y 15).

El palimpsesto e hipertexto más evidente en las coplas del carnaval de Cádiz son los fragmentos (cuartetas) que conforman el popurrí (o canciones en las agrupaciones ilegales) ya que esta parte del repertorio se basa en versionar canciones populares conocidas por una amplia mayoría ${ }^{10}$. Puede ocurrir que un espectador conozca antes el hipertexto del carnaval que el hipotexto en el que se basa. "A través de un doble proceso de instalación e ironización, la parodia señala cómo las representaciones presentes vienen de representaciones pasadas y qué consecuencias ideológicas se derivan tanto de la continuidad como de la diferencia." (Hutcheon, 1993: 187).

Como vamos a mostrar, el cine es uno de los hipotextos que está más presente en el carnaval. Si bien la relación entre cine y carnaval de Cádiz se produjo desde

1o Puede ocurrir, como en muchas comparsas, que las composiciones musicales del popurrí sean creadas en exclusiva para esa agrupación y no tengan como base canciones populares. 
prácticamente el nacimiento del séptimo arte, conviene recordar a título recopilatorio que el carnaval de Cádiz:

Como protagonista cinematográfico no tuvo apenas presencia hasta bien entrada la década de los 6o, es cuando se utilizan aquellas Fiestas Típicas como expresión folclórica secundaria y decorativa, ajena obviamente al concepto contestatario del carnaval, como un mero escaparate de la "gracia" gaditana, sin otorgarle un mínimo cariz artístico y relegándolo a una disciplina menor. Paralelamente, como era de esperar, la función informativa siempre estuvo presente en el carnaval y, en ese sentido, la aparición del cinematógrafo como invento clave para el siglo XX no fue una excepción (Sacaluga y Pérez, 2016: 310).

Asimismo, queda patente que los autores en muchas ocasiones no crean desde la nada, es decir, adaptan letras ya existentes. No hay plagio puesto que la creación deliberadamente quiere darse a conocer como versión de la original ya existente. La transtextualidad se da cuando el oyente de la nueva copla conoce la original, pero para alguien que no haya escuchado por ejemplo la original "Aquellos duros antiguos", decenas de veces versionada, la versión será una copla nueva. "En un texto que se quiere irónico, el acto de lectura tiene que ser dirigido más allá del texto (como unidad semántica o sintáctica) hacia un desciframiento de la intención evaluativa, por lo tanto, irónica del autor." (Hutcheon, 1981: 175).

El carnaval para provocar la risa se nutre, sobre todo, del realismo grotesco que es el "tipo específico de imágenes de la cultura cómica popular en todas sus manifestaciones" (Bajtin, 1990: 34). Esto es patente cuando las agrupaciones basan sus tipos en personajes de la vida cotidiana, pero como en esta investigación tratamos, en muchas ocasiones la base del personaje la toman de personajes de la cultura popular (pop) mundial y sobre ese personaje se añaden las características carnavalescas, andaluzas o gaditanas que quiera el autor.

$\mathrm{Al}$ crear un personaje desde otro ya reconocido por el gran público se agiliza el proceso de reconocimiento cognitivo por parte de los espectadores, pero a cambio, en el momento de la escritura de las coplas e interpretación hace ceñirse más al tipo, al personaje, para ciertos aspectos de la letra. "Comparsas, coros, chirigotas y cuartetos se han convertido en sujetos agentes y, a la vez, pacientes de una revolución viral cultural que no ha dejado de crecer y sofisticar una fiesta que nació a la sombra de la tradición oral y que hoy tiene visos de generar nuevos subgéneros culturales que la fusionan, la actualizan y modernizan" (Sacaluga y Pérez, 2016: 301).

En general, al tratarse de personajes de la cultura popular, el público reconoce rápidamente al hipotexto del hipertexto que están contemplando y escuchando. Aunque en el carnaval de Cádiz, pueden darse casos de que el espectador reciba antes el hipertexto que el hipotexto, es decir, que escucha la versión de una canción antes de escuchar la original (hipotexto) que dio lugar a la carnavalesca (hipertexto). Como aquí señala Genette: “¿Qué pasa con un hipertexto cuyo hipotexto se ha olvidado y que cada uno lee como un texto autónomo? Es claro que, en este caso, el estatuto de hipertexto se desvanece desde el momento en que el lector ya no tiene en mente" (Genette, 1989: 247). 
Los personajes de cómic cuentan con una gran ventaja a la hora de ser reconocidos de manera no verbal, simplemente por la apariencia el público reconoce a los personajes sin necesidad de que comiencen a cantar ya que:

El cómic aparece como tal en el siglo XIX junto a otros medios que comparten con él la característica principal de hacer uso conjunto de la imagen y del texto. La componente icónica permitió que su público incluyese a aquéllos cuyo dominio de la lengua del país en que se hallaban era deficiente. Conscientes del potencial de estos nuevos medios en ese sentido, los responsables de su producción entendieron que el uso de una tipología de personajes reconocible a simple vista facilitada su aceptación por el público en general (Jiménez, 2010: 109).

Recordemos que signo o representamen es algo que para alguien remite a otra cosa en algún aspecto o disposición (Peirce, 1987). Cuando los autores del carnaval de Cádiz deciden crear personajes y tipos para sus agrupaciones tienen dos puntos de partida básicos: personajes ya creados y modificados o personajes originales. Ni una ni otra opción son absolutas, es decir, basándose en un personaje ya creado (tema que aquí tratamos) no va a ser nunca igual que el original, ya que eso sería solo imitación (pastiche o plagio, además, destacar que se trata de un concurso de coplas, de creatividad de letra y música) y con los personajes originales, al igual que en el género de la narrativa, los autores se basan en personas existentes de las cuales extraen las características pertinentes a su creación (Fernández, 2020).

\section{Muestra}

Una vez hemos mostrado las bases teóricas en las que apoyamos nuestro estudio, procedemos a ejemplificar con casos producidos en el COAC ${ }^{11}$.

Observamos cómo los autores interpretan otros fenómenos provenientes de la también cultura popular como pueden ser los súper héroes (cómic), personajes de dibujos animados (cine) o de la literatura romántica (Drácula, zombies o Frankenstein) e incluso en cantantes.

Los propios nombres de las agrupaciones de cada año (paratextos) forman parte también del hipertexto ya que marcan las huellas del hipotexto, "El título, como un nombre de animal, sirve un poco de pedigrí y un poco de acta de nacimiento" (Genette, 1989: 51).

Ofrecemos en el Anexo I un listado de agrupaciones que hemos recopilado, las cuales tienen su hipotexto en la cultura popular.

Las dos coplas seleccionadas en este estudio son las presentaciones de Los Sgayderman, chirigota de 2014 y autoría de Pablo de la Prida y Las muchachas del Congelao, de 2009 y autoría de Antonio Pedro Serrano. Han sido seleccionadas estas y no otras debido a la claridad del traspaso del hipotexto al hipertexto, tanto de manera visual (disfraz y escenografía de la agrupación), musical y de contenido de las letras. Además, se conserva de manera accesible sus actuaciones en internet.

${ }^{11}$ Concurso Oficial de Agrupaciones Carnavalescas 


\subsection{Sgayderman ${ }^{12}$}

Los Sgayderman como su nombre (paratexto) muestra, consistía en una parodia del súper héroe de Marvel Spiderman, pero exponían que su característica principal era la homosexualidad ${ }^{13}$.

Ya estamos aquí / ya estamos aquí / ahora mismo yo te salvo a ti / ya estamos aquí / ya estamos aquí / el cielo ganao tengo por ti / Soy el mejor superhéroe / y ahora me lo vas a decir / porque tengo mucha gracia / pues no soy de otra galaxia / que yo soy de aquí, de aquí / iMira! / Hace un año fui al laboratorio por la piedra del riñón / mientras me analizaban la orina algo raro noté yo / una mariquita radioactiva en el cuello me picó / Yo de siempre he sido mariquita, pero con súper poderes es que soy maricón / Sgayderman, Sgayderman, vaya plan de sgayderman / Si llamas tú te ayudaré / Pero no me llames a las cinco que estoy viendo "Sálvame". / Siempre me transformo despacito y me arreglo súper bien / Yo no soy como Superman que cambia y nadie lo ve / porque se mete en una cabina y tarda cero coma dos / pero es que lo único que ha hecho es que se ha quitao las gafas y se ha puesto un caracol / Y mis poderes son de lo mejor / Uno es el sentido mariánnido / Porque si veo un mariquita / aunque no lo reconozca a ese lo percibo yo / Si veo a Raphael: / tiqui tiqui tí / O a Jaime Cantizano: / tiqui tiqui tí / Si veo a Camilo Sesto: / tiqui tiqui tí / Y hasta a Cristiano Ronaldo: / tiqui tiqui tí / Y con este público tan bueno, tan amable y sobre to tan respetable: / tiqui tiqui tiqui tiqui tiqui tiqui tí ya se me han quemao los cables. / Mira que soy gay, soy gay, soy gay / Manda una batseñal pa que me bailen por Cai / Que mire usted que gracia, / que mire usted que age, / que mire usted que gracia tiene el chavalín / Que mire usted que gracia, / que mire usted que age, / que mire usted que gracia tiene el chavalín / Pon pon se acabó.

\subsection{Las muchachas del Congelao ${ }^{14}$}

Las muchachas del Congelao consistía en la representación de todas las princesas Disney (once y una de Dreamwords):

Yo me quiero casar con un hombre educado / que nunca me interrumpa y que siempre me deje hablar / un mudo ideal. / ¿Quién es la más guapa de esta reunión? / Eres, eres, eres, eres, eres ¿̇ú? / Pero tú, ¿Pero tú como vas a ser? / Si tú eres de Dreamswork, tú no eres de Disney: / iFuera, fuera, fuera! / iAh! / iYa me habéis encabronao! / ¿Qué pasa que me estabais poniendo verde, no? / Las gordas aunque no salgamos en Disney también queremos cantar en el Falla. / Eres tú una mezcla entre Falete y el increíble Hulk / Las princesas aquí están / con el tatará tachín / y con la Bella Durmiente harta de tranquimazín / Y tenemos a Jasmine con la alfombra de Aladdín / Que en el aire se sostiene / de los ácaros que tiene / Con la Bella también, / que parece Esteticiene / Y a la Bestia le hace la depilación / Y la más chiquitilla / es la Campanilla y del nombre les doy la razón. / Niña ¿Pero por qué te llaman Campanilla? / Tolón tolón / tolón tolón / tolón tolón / Aquí están las princesas a ver quién me besa / aquí están, ya lo ven / las muchachas del Wald Disney.

\footnotetext{
12 Puede consultarse la actuación en https://www.youtube.com/watch?v=SnZEPbz58kI

13 Cuando se analiza y estudia el carnaval de Cádiz es fundamental tener en consideración la época y contexto en el que las coplas son creadas.

14 Puede consultarse la actuación en https://www.youtube.com/watch?v=stqD8-LtPsM 00.123.10
} 


\section{Discusión}

Las agrupaciones que mostramos en el listado, además del paratexto, del nombre, dentro del repertorio también hay restos del hipotexto ya que:

El hipertexto debe permanecer constantemente en el prolongamiento de su hipotexto al que debe solamente llevar hasta una conclusión prescrita o congruente, vigilando la continuidad de ciertos datos como la disposición de los lugares, el encadenamiento cronológico, la coherencia de los caracteres, etc. (Genette, 1989: 202).

Vamos a ver las trasformaciones que sufren los hipotextos para convertirse en hipertextos.

\begin{tabular}{|c|c|}
\hline Agrupación & Procedencia 15 \\
\hline Spiderman/Sgayderman & $\begin{array}{c}\text { Cómic y televisión de cuando los autores } \\
\text { eran pequeños }\end{array}$ \\
\hline Hipotexto - Personaje & Hipertexto - Carnaval \\
\hline $\begin{array}{l}\text { El uniforme } \\
\text { Música de la serie de televisión } \\
\text { Tener un súper poder }\end{array}$ & $\begin{array}{l}\text { Colores cambiados } \\
\text { Maquillados } \\
\text { Horquillas } \\
\text { Mantón de manila en lugar de } \\
\text { telarañas } \\
\text { La araña pasa a ser el insecto } \\
\text { mariquita } \\
\text { El sentido arácnido pasa a ser } \\
\text { sentido "mariánnido" } \\
\text { Describen a su manera a Superman } \\
\text { Aparece Batman cuando pertenecen } \\
\text { a universos diferentes DC y Marvel }\end{array}$ \\
\hline
\end{tabular}

Tabla 1. Sgayderman. Elaboración propia

\begin{tabular}{|c|c|}
\hline Agrupación & Procedencia \\
\hline $\begin{array}{l}\text { Princesas Disney/Las muchachas del } \\
\text { Congelao: }\end{array}$ & $\begin{array}{l}\text { Desde pequeño } \\
\text { Las hijas del autor tenían } 9 \text { años, } \\
\text { veían mucho las películas y no le } \\
\text { gustaba a él el mensaje que } \\
\text { transmitían }\end{array}$ \\
\hline Hipotexto - Personaje & Hipertexto - Carnaval \\
\hline $\begin{array}{l}\text { Tipos (disfraces) muy detallados, } \\
\text { ropas en movimiento consiguiendo } \\
\text { gran parecido al dibujo de la película } \\
\text { Música de las películas de Disney } \\
\text { Hilo conductor (tratan temas de } \\
\text { ellas) } \\
\text { Acaban con las posturas de ellas }\end{array}$ & $\begin{array}{l}\text { Fiona es el resultado de unir Falete }{ }^{16} \\
\text { y a Hulk } \\
\text { Bella Durmiente: Tranquimacín } \\
\text { Jasmine: Alfombra vuela con ácaros } \\
\text { Bella: depila a la Bestia } \\
\text { Campanilla: "Campanillas" }\end{array}$ \\
\hline
\end{tabular}

Tabla 2. Las muchachas del Congelao. Elaboración propia.

\footnotetext{
15 El apartado de "Procedencia" es la respuesta a la pregunta que en el apartado de Metodología explicábamos que hemos recurrido a los autores para poder cumplimentar este apartado. Con procedencia nos referimos al modo de inspiración y cómo conocieron los datos del hipotexto, del personaje parodiado.

${ }_{16}$ Conocido cantante español.
} 
Ambas agrupaciones, en el resto de repertorio (pasodobles, cuplés y popurrí) siguen haciendo alusión a sus personajes para subrayar la procedencia de estos.

Destacamos que muchas veces "un hipotexto es considerado mentiroso, y el hipertexto se presenta como restablecedor de la 'verdadera historia'" (Genette, 1989: 456). En otro momento del repertorio, Las muchachas del Congelao cantan: "Ahora les contaré lo que siempre oculté, mi secreta y verdad de la historia, que es más bien, pa contarla en 'La noria'17". Por otro lado, los Sgayderman argumentan que ellos saben el verdadero motivo por el cual Superman no tarda nada en cambiarse de ropa. Este hecho, contar y cantar "la verdad" es un recurso usado en el carnaval de Cádiz de manera humorística cuando el personaje habla sinceramente al público.

La rearticulación de estos personajes como hemos visto es una tarea complicada ya que extrapolan al hipotexto del medio originario y se traspasa al teatro. Del cómic (y ya películas) de Spiderman, y de las películas de animación de Disney. En el caso del súeper héroe la dificultad residía en el súper poder de las telarañas y el sentido arácnido que la agrupación solventa con unas luces led en el pecho y un mantón de manila en lugar de las telarañas. El forillo (telón de fondo) representaba edificios, por los que suele transitar este personaje de cómic. Por otro lado, las princesas Disney el mayor hándicap que tenían era pasar de un personaje muy visual de dos dimensiones a tres. Además, está el añadido de que en la ficción todas son mujeres jóvenes y en la chirigota todos son hombres. Aquí, apreciamos una de las características fundamentales de esta fiesta: la inversión carnavalesca, hombres disfrazados de mujeres. Esto fue solventado con un muy elaborado tipo (disfraz) que pudo representar el dinamismo de los dibujos animados a las telas preparadas para causar ese efecto junto a un detallado maquillaje. El forillo en el caso de estas princesas era un paisaje campestre de dibujos animados y al fondo se divisaba un castillo. Todos estos cambios del personaje original al carnavalesco se hacen teniendo siempre presentes las características del hipotexto para que su resultado, el hipertexto, sea fiel, reconocible, pero sin ser una copia, de ahí los elementos carnavalescos añadidos que hemos expuesto.

\section{Conclusiones}

Con este trabajo demostramos que el carnaval de Cádiz además de ser cultura popular, en muchas ocasiones, y siguiendo los postulados de Genette, es hipercultura popular.

Vemos que en estas creaciones los signos son motivados y no arbitrarios. La arbitrariedad aparece en la adaptación de esos signos del hipotexto al hipertexto.

El hipertexto no tiene por qué ser fiel al referente en todos los aspectos. Por ejemplo, en "La maldición de la lapa negra" (chirigota ganadora de 2019), el personaje principal, y uno de los autores de la agrupación, va vestido como el personaje de la segunda entrega de Piratas del Caribe, pese a que en el nombre, en el paratexto, se hace alusión a la primera entrega. Con lo cual, los autores del carnaval de Cádiz

17 Programa de televisión español semanal emitido por Telecinco desde 2007 hasta 2012, donde se trataba desde la llamada prensa rosa, prensa del corazón, a sucesos y reportajes de diferente índole. 
juegan con el proceso semiósico para producir creaciones culturales. Saben que su obra parte de otra anteriormente conocida por el público que le transmitirá mayor potencial comunicativo.

Tras este estudio, un resultado inesperado ha sido la recopilación de agrupaciones con esta temática que pudiera resultar útil para estudios posteriores de esta materia. Y surgen más preguntas de investigación, para direcciones futuras, sobre esta manifestación cultural ¿Existen patrones por año?, ¿Qué efectos tienen las series de televisión de moda en el carnaval de Cádiz?, ¿Qué cultura popular es más habitual, la nacional o la internacional? Estas preguntas vienen a demostrar, una vez más, lo mucho que se puede estudiar este fenómeno cultural y comunicacional que es el carnaval de Cádiz.

Queda demostrado el carnaval de Cádiz y su creatividad son abordables desde múltiples disciplinas. Aquí han estado presentes la audiovisual, histórica y literaria. Es un fenómeno cultural que poco a poco se abre camino en la academia.

\section{REFERENCIAS}

Bajtín, M. (1990). La cultura popular en la Edad Media y en el Renacimiento. El contexto de François Rebelais. Madrid: Alianza.

Barcelón Calatayud, A. (2014). El tipo en el carnaval de Cádiz. Propuesta para una catalogación. [Tesis doctoral]. Universidad de Cádiz.

Barcelón, Ana (2015). El tipo en el carnaval de Cádiz. Propuesta para una catalogación. Cádiz: Q book.

Bécquer, G.A. (1862). “El Carnaval”, en El Contemporáneo. Periódico, Digitalizado por Librodot.com, 5 de marzo. Recuperado de: http://severitorres.org/ampa/joomla/ images/Biblioteca/B/Becquer/carnaval\%20el.pdf.

Bello, N. (2019). “Estrella Fernández: `Los que no quieren ver cultura en el Carnaval están equivocados'". Ocadizdigital, 7 de julio. Recuperado de http://ocadizdigital.es/ noticia/c\%C3\%A1diz/estrella-fern\%C3\%A1ndez-losque-no-quieren-ver-cultura-en-el-carnaval-est\%C $3 \%$ Ann-equivocados

Fernández Jiménez, E. (2016). El potencial comunicativo de las chirigotas gaditanas y su realización televisiva. [Tesis doctoral] Universidad de Sevilla.

Fernández Jiménez, E. (2018). La final del Falla. Un estudio sobre la realización televisiva del COAC. Cádiz: Servicio de publicaciones de la Universidad de Cádiz.

Fernández Jiménez, E. (2020). "El proceso creativo de las agrupaciones carnavalescas de Cádiz”. Vivat-Academia Revista de Comunicación, 153, pp. 29-53. http://doi.org/10.15178/ va.2020.153.29-53

García Gallardo, F.J. (2002). Música y agrupaciones de carnaval: Huelva y Cádiz. [Tesis doctoral]. Universidad de Huelva. 
Genette, G. (1989). Palimpsestos. Literatura en segundo grado. Madrid: Taurus.

Hutcheon, L. (1981). "Ironía, sátira, parodia. Una aproximación pragmática a la ironía" (publicado originalmente en la revista Poetique, 45, París, febrero de 1981, pp. 173-193, traducción de Pilar Hernández Cobos).

Hutcheon, L. (1993). "La política de la parodia postmoderna". Criterios, La Habana edición especial homenaje a Bajtín. pp. 187-203 [original de «The Politics of Postmodern Parody», en H. F. Plett (ed.), Intertextuality, Berlín-Nueva York, Walter de Gruyter, 1991, pp. 225-236].

Jiménez Varea, J. (2001). "Símbolos y estereotipos: la moral a través de la imagen en el cómic”, en J.D. Fernández, C. Lasso de la Vega y A. Pineda (coords.), El cómic en el nuevo milenio. Actas de las primeras jornadas sobre cómic, comunicación y cultura (pp. 109-118). Sevilla: Universidad de Sevilla.

López, R. (1998). “Carnaval y Cádiz: Una cultura insólita”. En Alberto Ramos, IX Congreso del Carnaval (pp. 343-354). Cádiz: Ayuntamiento de Cádiz.

Medina Tamayo, D. (2017). Cómo hacer una agrupación callejera del Carnaval de Cádiz. Cádiz: Macnulti.

Moreno Tello, S. (2015). El carnaval silenciado: golpe de Estado, guerra dictadura y represión en el febrero gaditano (1936-1945). [Tesis doctoral]. Universidad de Cádiz.

Osuna García, J. (2009). El periodismo en tiempos de Carnaval. 1763-2005 (más linotípico no lo hay). Cádiz: Quorum Editores.

Páramo Fernández-Llamazares, M.L. (2016). El carnaval de Cádiz como factoría de literatura popular. [Tesis doctoral]. Universidad Complutense de Madrid.

Páramo Fernández-Llamazares, M.L. (2017). El carnaval de las coplas, un arte de Cádiz. Madrid: Izana.

Roiz, M. (1982). "Fiesta, comunicación y significado". En Honorio M. Velasco (ed.), Tiempo de Fiesta. Ensayos antropológicos sobre las fiestas en España (pp. 95124). Madrid: Tres-Catorce-Diecisiete.

Sacaluga Rodríguez, I. (2014). El carnaval de Cádiz como generador de información, opinión y contrapoder: análisis crítico de su impacto en línea y fuera de línea. [Tesis doctoral]. Universidad Complutense de Madrid.

Sacaluga Rodríguez, I., y Pérez García, A. (2016). Carnaval de Cádiz y cine, una relación recíproca. Periférica Internacional. Revista Para El Análisis De La $\begin{array}{llllll}\text { Cultura } & Y & \text { El } & \text { Territorio, } & \text { Recuperado de }\end{array}$ https://revistas.uca.es/index.php/periferica/article/ view/3284

Solís Llorente, R. (1966). Coros y Chirigotas. (Las letras del Carnaval gaditano). Madrid: Tauro Ediciones.

Vázquez Medel, M.A. (1994). La construcción cultural de Andalucía. Sevilla: Alfar. 


\section{ANEXO I}

1. Troupe de Charlots Sangolotinos, 1918

2. Charlot, Chispa y sus botones, 1925

3. Los Mikeys, 1934

4. Los cuentos de Calleja, 1935

5. Popeye, Rosario y sus niños. Chirigota, 1950

6. Robin y sus arqueros. Coro, 1952

7. Alí Bába y los 40 ladrones. Coro, 1953

8. La policía montada del Canadá. Coro, 1954

9. Los mosqueteros. Coro, 1955

10. Blanca Nieve y los 7 Enanitos, 1955

11. El sombrero de tres picos. Coro, 1957

12. Los Charlots de Candilejas, 1958

13. Las huestes de Don Nuño. Chirigota, 1959

14. Los bartolos vagos. Comparsa, 1960

15. Los Aladino y la lámpara maravillosa. Chirigota infantil, 1960

16. Los Cuasimodos. Comparsa, 1961

17. Los ratoncitos Pérez. Chirigota infantil, 1961

18. Los enanito del bosque. Coro, 1963

19. Los Beatles de Cádiz. Chirigota, 1965

20. Los quijotes. Comparsa, 1962

21. Los don Juan de Zorrilla. Coro, 1966

22. Mary Poppins y su conjunto. Comparsa, 1969

23. Los Cantinflas, 1969

24. Los Popeyes. Chirigota, 1962

25. Los Charlots. Comparsa, 1963

26. Los don Cicuta. Chirigota, 1963

27. Los Picapiedra. Chirigota, 1963

28. Los Zipi y Zape. Chirigota, 1971

29. Don Mendo y sus mendas lerendas. Cuarteto, 1973

30. Los Charlots, 1973

31. Los Picapiedras. Chirigota, 1973

32. Don Juan Tenorio y los que fueron al velatorio. Cuarteto, 1975

33. Don Anacleto y sus tres analfabetos. Cuarteto, 1977

34. Los Tip y Coll. Chirigota, 1977

35. Fantasía de Walt Disney. Comparsa infantil, 1977

36. Al Capone y sus matones. Chirigota infantil, 1977

37. Recordando a Maurice Chevalier. Comparsa, 1978

38. Los geyperman. Comparsa infantil, 1978

39. Los Charlies River. Comparsa, 1979

40. Los simios. Comparsa, 1980

41. Paco Sandía y sus zagales harto garbanzos. Chirigota, 1980

42. Mario Carmelo y sus muñecos. Cuarteto, 1980

43. El comandante Custok y los que se tiran al pilón. Cuarteto, 1980

44. Los supermanes. Chirigota infantil, 1980

45. Los vampiros tajarinas. Chirigota, 1981

46. La saga de los porretas. Chirigota, 1981 
47. Grandes relatos. Cuarteto, 1981

48. Oliver Twist. Comparsa infantil 1981

49. El flautista de Hamelín. Comparsa infantil 1981

50. Pinocho. Coro, 1982

51. Siete novias para siete hermanos. Comparsa juvenil, 1982

52. Los Tom Sawyer. Chirigota juvenil, 1982

53. Botones chirigota infantil 1985

54. Los supermantas, 1985

55. Cine cómico. Chirigota, 1983

56. Dallas. Cuarteto, 1983

57. TBO. Chirigota, 1984

58. Las abejas de Ruinasa. Chirigota, 1984

59. Ghandi. Comparsa, 1984

60. Los supermantas. Chirigota, 1985

61. Zombies. Comparsa 1985

62. La viudita naviera. Coro, 1986

63. Hombres Lobo. Comparsa, 1986

64. El loco de la mancha y una mancha de locos. Cuarteto, 1986

65. Pero por quién puñetas doblan las campanas. Cuarteto, 1986

66. El cuarteto siempre llama dos veces. Cuarteto, 1987

67. Scaramuch. Comparsa juvenil, 1987

68. Quo Cadix. Coro, 1988

69. Camelot. Coro, 1988

70. Me borras de África. Cuarteto, 1988

71. Chacolín. Comparsa juvenil, 1988

72. Pasaje a la India. Coro, 1989

73. Miky Jackson y los Bitter cal. Chirigota, 1989

74. Los santos inocentes. Chirigota, 1990

75. Bátmonos que nos vamos. Coro, 1990

76. Los gallifantes. Chirigota infantil, 1990

77. Los Joselitos de la voz de oro, Cuarteto infantil, 1990

78. Los nenes de la Dolce Vita. Cuarteto infantil, 1991

79. Batillo. Comparsa infantil, 1992

80. Los boin boin boin y no vamos de James Bown. Chirigota juvenil, 1992

81. Inocente, Inocente. Coro, 1994

82. Caiman. Chirigota, 1994

83. Blancanieves y los siete enanitos. Chirigota, 1997

84. Ser o no ser. Cuarteto, 1997

85. Los extraterrestres. Chirigota, 1998

86. Los malos de la película. Chirigota, 1999

87. Los rockeros de la puebla. Chirigota, 2000

88. Ozú... Opá. Cuarteto, 2002

89. Don Quijote conservantes y colorantes. Chirigota, 2003

90. Los doctores Jeckyll. Chirigota, 2005

91. Robinson de la isla. Chirigota, 2006

92. El Código Da Viñi. Chirigota, 2008

93. Pal desembarco Nosmardía. Cuarteto, 2008

94. Los perfumistas. Comparsa, 2008 
95. Los Monstruos de pueblo. Chirigota, 2008

96. Las malas, malas que te cagas. Cuarteto, 2008

97. Las muchachas del congelado. Chirigota, 2009

98. Cuando yo me pele. Coro, 2009

99. Los caballeros de la piera reonda. Comparsa, 2010

100. Los lunnis al zolesito, tikipo, tikipo popopo!!! Cuarteto juvenil, 2010

101. La Pandilla Basurilla. Cuarteto juvenil, 2010

102. Los encantadores de perros. Chirigota, 2011

103. Los sgayderman. Chirigota, 2011

104. Las locuras de Martín Burton. Comparsa, 2011

105. Los Joaquín Pamplina, cantautor de la Plaza Mina. Chirigota, 2011

106. Ni Gran hermano, ni sálvame, ni un partido del Madrid contra el Nástic, lo mejor del 2011, "Me cago en tus castin" Cuarteto juvenil, 2011

107. El padre Carrasco y las niñas que dan asco. Chirigota, 2012

108. Los superhéroes. Comparsa, 2012

109. Ciudadano Zero. Comparsa, 2012

110. Los protagonistas. Chirigota, 2012

111. Esto no hay quien lo salve. Chirigota, 2012

112. Bollywood. Coro, 2012

113. Drácula de Gran Estoque. Cuarteto, 2012

114. Los telecadi (una chirigota infantí) Chirigota juvenil, 2012

115. Los gatos callejeros. Comparsa, 2013

116. Los de gris. Chirigota, 2013

117. Robín de El Bosque y los demás de Ubrique. Cuarteto, 2013

118. Los caca-fantasmas. Cuarteto infantil, de 2013

119. La Marvel que me parió. Chirigota juvenil, 2014

120. Hoy no me puedo levantar. Chirigota, 2014

121. El club de los Poetas Bajitos. Chirigota infantil, 2014

122. Justin Bieber y los demás sobreviven. Cuarteto infantil, 2014

123. Mayta vende kas y Popá coca cola light. Cuarteto infantil, 2014

124. Los seguidores del Arturito. Chirigota, 2015

125. Cuento de tronos. Cuarteto, 2016

126. Las aventuras de Tontín. Cuarteto, 2016

127. Los que viven de gañote. Chirigota, 2016

128. Los gemeliers de la calle Barrié. Cuarteto juvenil, 2016

129. Lo que el viento se llevó. Cuarteto, 2017

130. Los Indiana Jones de los Callejones. Chirigota, 2017

131. El equipo A minúscula (Comando Caleti). Cuarteto, 2018

132. El Diablo se viste de coro. Coro, 2018

133. La maldición de la Lapa Negra. Chirigota, 2019

134. Los superminihéroes. Chirigota infantil, 2019

135. Harry Potera y la piedra sofá. Cuarteto infantil, 2019

136. Lo siento Pixar, no todo el mundo puede ser de Cádiz. Cuarteto infantil, 2020

137. Marvel no hay más que una. Cuarteto infantil, 2020

138. La casa de papel colorao. Comparsa juvenil, 2020

139. La casa de los papelillos. Chirigota, 2020 